\title{
Follow-up study on premature infants with and without retinopathy of prematurity
}

\author{
Rosemary Robinson, Michael O'Keefe
}

\begin{abstract}
The ocular complications in population of 131 premature infants, with and without retinopathy of prematurity (ROP) are reported. An increased incidence of strabismus $(20 \%$ with ROP and 25\% without ROP) and myopia (27.5\% with ROP and $8.8 \%$ without $R O P$ ) was shown. Significant visual loss occurred in $10.7 \%$ overall, increasing to $35 \%$ with stage 3 disease and $100 \%$ with stage 4 . With the increased survival rate of premature infants, the relevance to future management of this expanding group of young people is considered.

(Brf Ophthalmol 1993; 77: 91-94)
\end{abstract}

Retinopathy of prematurity (ROP) is a leading cause of blindness in children and one of the commonest causes of blindness in the perinatal period.' The incidence of ROP has increased in recent years, owing to improvement in the survival rate of low birth weight infants. ${ }^{234}$ Gibson et al examined, in detail, the incidence of ROP-induced blindness from 1952-1986, in British Columbia. They showed that since the mid 1960s there has been an increase in the total incidence of ROP-induced blindness and that this is due principally to increased survival of infants weighing 750-999 g. Phelps et al estimated that 550 children go blind every year from ROP, in the United States.

Since 1988 cryotherapy has become the accepted mode of therapy in advanced disease and reduced the poor outcome from $47 \cdot 7 \%$ to $25 \cdot 7 \%$ at 1 year of age. ${ }^{6}$ As ophthalmologists can now influence the outcome of this disease, active screening of these infants should be mandatory. This has also led to an increased number of premature children attending paediatric ophthalmology units. In this study, we examined the incidence of ocular complications in a population of premature children who attended the ophthalmology unit, at the Children's Hospital, Dublin.

\section{Methods}

All premature neonates born in three maternity hospitals in Dublin were screened by the consultant staff of the Children's Hospital. These three hospitals deliver 18000 infants per year, with $0.8 \%$ under $1500 \mathrm{~g}$ at birth, and $0.6 \%$ (108) surviving beyond the neonatal period. This premature population of neonates accounts for about a third of all premature infants born in the Republic of Ireland each year. We began an active screening programme in each hospital in January 1986 . All infants, born under 30 weeks' gestation and/or birth weight under $1500 \mathrm{~g}$, are first screened at 6 weeks. When discharged from the neonatal unit, they continue to attend for follow up at the Children's Hospital. Follow up is determined by the degree of vascularisation of the retina. If fully vascularised, the child is seen again at 3 months and then yearly until age 5 years, unless strabismus or amblyopia develop. If ROP is diagnosed, assessment is every 3-4 weeks if stage $1-2$ is present and weekly if stage 3. If stage 3 threshold disease is noted then cryopexy is applied. After treatment, all infants are seen at 3 monthly intervals for the first year and every 6 months for 5 years, then annually.

We classified ROP according to the international classification ${ }^{7}$ and defined significant ROP as stage 3 or 4 disease. Since 1986, infants who reached stage 3 threshold disease, as defined by the CRYOROP group, ${ }^{8}$ (that is, stage $3+$ disease involving five contiguous or eight cumulative 30 degree sectors in zone 1 or zone 2) received cryotherapy. This subgroup has been discussed elsewhere.'

This prospective study examines the outcome of 131 premature children born between January 1983 and December 1990, who were screened during the neonatal period and continue to attend the Children's Hospital for assessment. A total of 117 were born after January 1986; all were under $1500 \mathrm{~g}$ or under 30 weeks' gestation at birth. ROP was present in 160 eyes and 102 eyes were normal.

Follow-up assessment included visual acuity, orthoptic assessment, cycloplegic refraction, and funduscopy. The method of visual assessment included fixation patterns, Sheridan Gardiner, Allen picture cards, and Snellen acuity, depending on the age and mental ability of the child.

\section{Results}

A total of 131 infants, with 262 eyes, form the study; 102 (39\%) eyes were normal. Stage 1 ROP was noted in $75(29 \%)$ eyes, stage 2 in $37(14 \%)$ eyes, stage 3 in 34 (13\%) eyes and $14(5 \%)$ eyes had stage 4 disease. Zone 2 of the retina was affected in 56 eyes and zone 3 in 96 eyes. Since 1986, we applied cryotherapy for stage 3 threshold disease to $21(8 \%)$ eyes; four $(1 \cdot 5 \%)$ eyes had retinal detachment repair.

Figures 1 and 2 show the distribution of ROP, within the cohort, versus gestational age and birth weight, respectively. Gestational age was not documented in six eyes. Thirty eyes were from infants of under 26 weeks' gestation. Of these, $25(83 \%)$ developed ROP, including nine (30\%) with significant disease (stage 3 or 4 ). Of the 60 eyes with gestational age between 26-28

Temple Street, Dublin

R Robinson

Correspondence to:

Mr Michael O'Keefe,

Department of
} 
weeks, 51 (85\%) developed ROP, including 20 (33\%) with significant disease. Between 28-32 weeks' gestation, 80/164 (49\%) developed ROP, with $17 / 164(10 \%)$ having significant disease. ROP was not seen in two eyes of over 32 weeks' gestation.

Birth weight was not documented in 30 eyes. Forty two $(75 \%)$ of 56 eyes, in infants under $750 \mathrm{~g}$, developed ROP, including $11(20 \%)$ with significant disease. There were 84 eyes in infants between 750-100 g; 66 (79\%) developed ROP, with 27 (32\%) having significant disease. Ninety

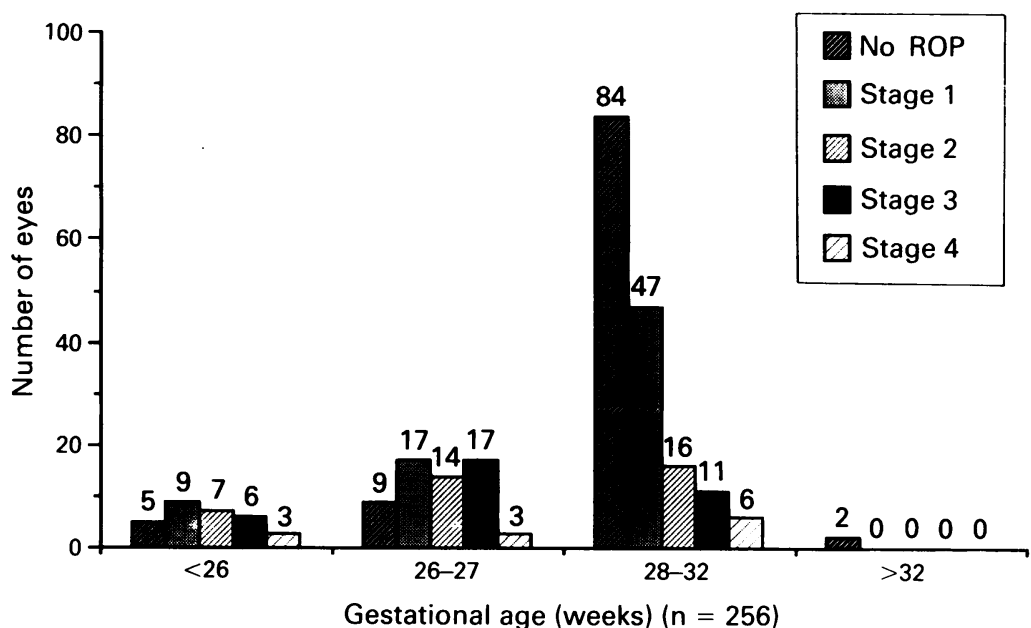

Figure 1 The distribution of ROP vs gestational age.

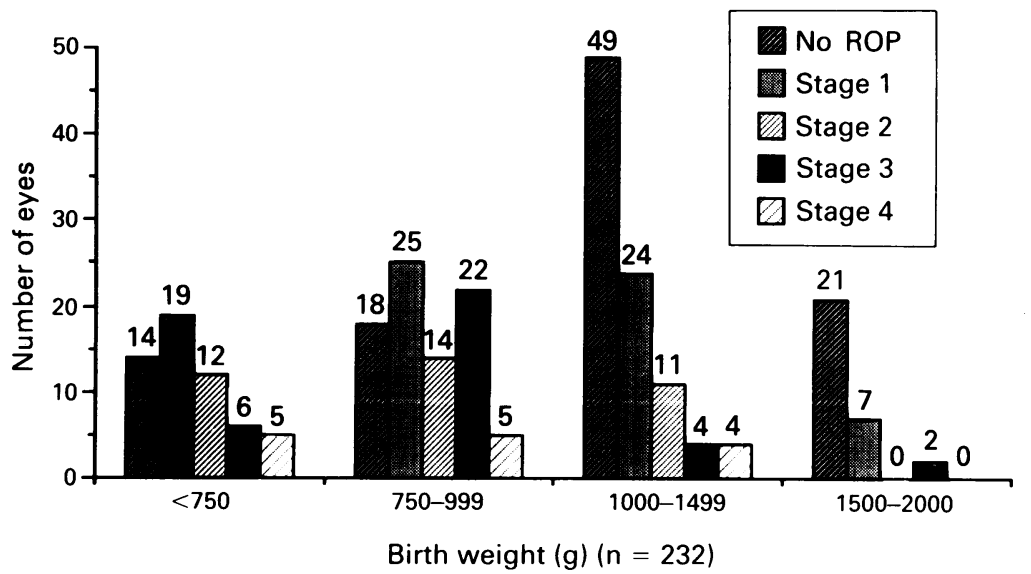

Figure 2 The distribution of ROP vs birth weight.

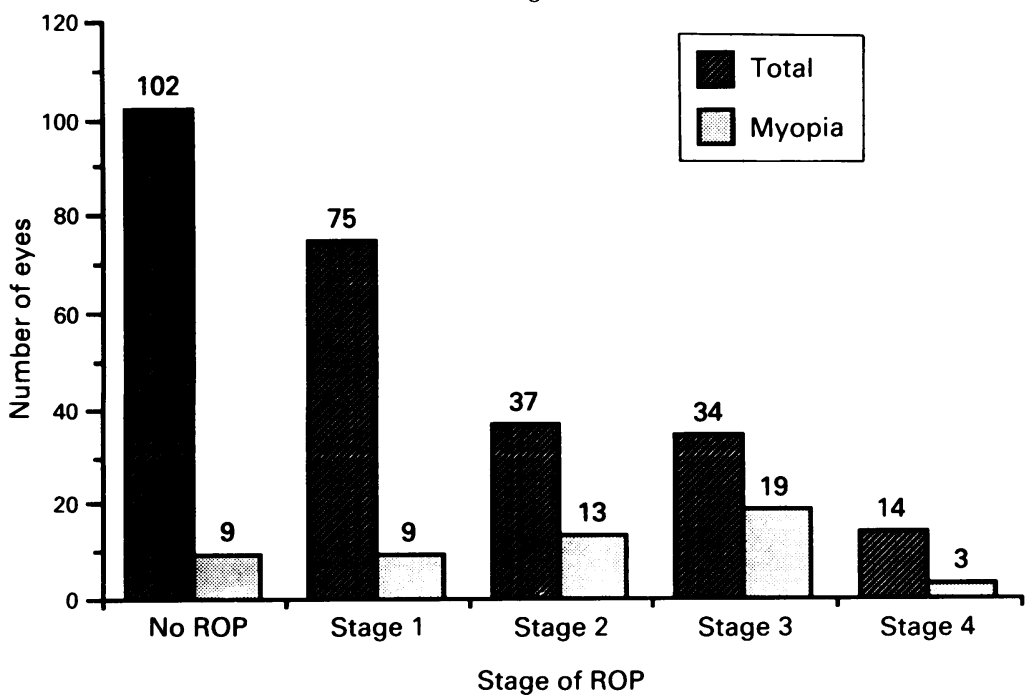

Figure 3 The incidence of myopia associated with each stage of ROP. two eyes were from infants with weights between $1000-1500 \mathrm{~g} ; 43$ (47\%) had ROP, of which eight (9\%) had significant disease. At between 1500 $2000 \mathrm{~g}, 7 / 30(23 \%)$ developed ROP and 2/30 (7\%), had significant disease.

A total of $217(82.9 \%)$ had a normal retinal outcome. Cicatricial disease developed in 14 $(5 \cdot 3 \%)$ eyes. Total retinal detachment occurred in $17(6.5 \%)$, seven of which developed microphthalmos. Cryotherapy scars, with a normal posterior pole, were noted in $10(3.8 \%)$ eyes. Four $(1 \cdot 5 \%)$ eyes, with documented ROP, had peripheral scars unrelated to cryotherapy.

Significant visual loss, that is, visual acuity $<6 / 60$, Snellen equivalent, developed in 28 $(10 \cdot 7 \%)$ eyes. Twenty five $(89 \%)$ had significant ROP. Two eyes in one infant had stage 1 disease. Poor vision was due to optic nerve hypoplasia rather than ROP. One eye, without ROP, had strabismic amblyopia. The incidence of poor vision with stage 3 was $12 / 34(35 \%)$ and $100 \%$ with stage 4 disease.

Myopia was noted in 53 eyes ( $>-1.00$ DS spherical equivalent). Figure 3 shows the distribution of myopia within the group. Of those eyes which were normal, nine $(8 \cdot 8 \%)$ developed myopia, nine (12\%) with stage 1 and $13(34 \%)$ with stage 2 disease. A significant increase, 19 (56\%), occurred with stage 3 disease.

Strabismus developed in $29(22 \%)$ children. Twenty eight had an esotropia. ROP was present in $17(20 \%)$ and $12(25 \%)$ were normal. Seven had documented intraventricular haemorrhage (IVH). Ten were excluded as two were blind from ROP, three had uniocular cicatricial disease, one had cryotherapy to one eye only, three had optic nerve hypoplasia $(\mathrm{ONH})$ and one had optic atrophy. Primary strabismus was therefore present in $19(15 \%)$ children, $10(11 \%)$ with ROP, and nine $(21 \%)$ without ROP. Seventeen $(66 \%)$ had early onset, nonaccommodative strabismus. Two children, with onset of strabismus after 2 years, did not have ROP. Amblyopia developed in seven $(5 \cdot 3 \%)$ children. Three responded to occlusive therapy. Four were unresponsive. This group included one child with nystagmus, one with anisometropia, and one microtropia. Corrective surgery was performed in nine $(6.9 \%)$ cases.

Four (3\%) infants had bilateral OHN, three with ROP. This diagnosis was made clinically, by one observer (MOK), when a small optic nerve head, associated with a double ring sign was noted using a direct ophthalmoscope. Only one child has normal visual acuity. All weighed less than $1000 \mathrm{~g}$ at birth. One $(0.76 \%)$ child, without ROP, had optic atrophy associated with hydrocephalus, secondary to IVH. One $(0 \cdot 76 \%)$ infant, with stage 4 retinopathy, had bilateral trabeculectomies for glaucoma. One child had a VI nerve palsy, secondary to IVH. Three $(2 \cdot 2 \%)$ infants had nystagmus, two with ROP (Table I).

\section{Discussion}

Ocular morbidity is now well recognised as a complication of prematurity. In this study, 217 $(82.9 \%)$ eyes had a normal retinal outcome. The incidence of poor visual outcome - that is, vision $<6 / 60$, increased to $56 \%$ when stage 3 disease 
Table 1 Summary of ocular complication in 71 eyes

\begin{tabular}{lcl}
\hline Ocular complications & No of eyes & Association with ROP \\
\hline $\begin{array}{l}\text { Total retinal detachment } \\
\text { Cicatricial disease }\end{array}$ & 17 & all had significant ROP \\
$\begin{array}{l}\text { Peripheral scars } \\
\text { (non-cryotherapy) }\end{array}$ & 14 & all had significant ROP \\
$\begin{array}{l}\text { Cryotherapy scars only } \\
\text { Microphthalmos }\end{array}$ & 10 & all had significant ROP \\
Glaucoma & 7 & all had significant ROP \\
Optic nerve hypoplasia & 8 & all had significant ROP \\
Optic atrophy & 2 & all had significant ROP \\
Nystagmus & 6 & no ROP ROP \\
Sixth nerve palsy & 1 & 4/6 had ROP \\
& & stage 1 ROP \\
\hline
\end{tabular}

was realised. Cats and $\operatorname{Tan}^{10}$ noted in their study that $6 / 7$ children with stage 3 disease had subsequent visual problems, though they failed to specify the actual visual acuity. Microphthalmos is a well recognised feature of cicatricial ROP. This occurred in seven cases in our series. Though our numbers are too small for statistical analysis we agree with Kelly and Fielder ${ }^{11}$ that this is probably a retardation of eye growth rather than true microphthalmos. Optic atrophy and sixth nerve palsy reflect cerebral insults suffered by two children during the neonatal period.

Only one child had a vision of $<6 / 60$ with stage 1 disease. This child had ONH. Three other children also had $\mathrm{ONH}$, two with reduced $(6 / 60$ $6 / 18$ ) and one with normal vision. This high incidence of ONH had not been reported previously. Fielder et $a l^{12}$ comment that the diagnosis of milder degrees of $\mathrm{ONH}$ is problematic in this population owing to the common but unreported incidence of the double ring sign in premature babies (a personal observation). Burgess and Johnson ${ }^{13}$ reported one case of bilateral ONH in their series of 49 infants with extremely low birth weight and low gestational age. All our children with $\mathrm{ONH}$ were less than $1000 \mathrm{~g}$ at birth. All had IVH. In a recent review of ONH in children, Zeki and Dutton ${ }^{14}$ state that an insult in the developing optic nerve, on or around the $17 \mathrm{~mm}$ stage of embryonal development, results in ONH. They did not report an association between $\mathrm{ONH}$ and prematurity. Burke $e t$ al reported a series of 46 children with ONH of which 12 were premature infants. They suggest that the occurrence of $\mathrm{ONH}$ and hypoxic ischaemic brain injury, with or without ROP may have a common aetiological factor in these children. The high incidence of $\mathrm{ONH}$, in our premature population, may reflect cerebral insults suffered during the early stages of intrauterine development. It also raises the question that the same insult may have contributed to premature birth in these children.

Myopia in ROP is thought to be a combination of axial and lenticular changes. ${ }^{16}$ The incidence of myopia, in this study, was $27.5 \%$ with ROP and $8.8 \%$ without ROP. The peak incidence, $56 \%$, was in stage 3 disease. Eyes with stage 4 disease were not refracted, as retinoscopy was not possible in many of the children, owing to retinal detachment. Other studies have reported $29-50 \%$ with ROP and $10-15 \%$ without ROP. ${ }^{1013} 1^{17-22}$ The high incidence of myopia in this ROP group compared with other studies reflects the high incidence of stage 3 disease in our population. Schaffer $e t a l^{17}$ had an incidence of $17 \%$ with ROP and $8 \%$ without ROP, but included only those with stage 1 and 2 disease. Gallo and Lennerstrand ${ }^{18}$ did not specify the incidence of ROP within their premature population. Snir et $a l^{19}$ examined children with and without cicatricial ROP. Their incidence of myopia was $50 \%$ in those with cicatricial disease. This is in keeping with our incidence of myopia with stage 3 disease (54\%). Nissenkorn et $a^{20}$ also showed a positive correlation between the degree of myopia and severity of cicatricial disease. We are reviewing myopia in our children with ROP, in greater detail, particularly in light of the use of cryotherapy and longer term assessment. This will be the subject of a further paper.

The overall incidence of strabismus was $20 \%$ with ROP and $25 \%$ without ROP. Snir et al recorded a similar picture. ${ }^{19}$ They also included children with cicatricial disease. When we exclude those with poor vision, due to ROP or optic nerve lesions, our incidence of strabismus, with ROP, is $11 \%$. This is more in keeping with Schaffer $e t a l^{17}$ who also noted $11 \%$. Keith and Kitchen $^{22}$ comment that strabismus increases significantly once stage 3 disease is realised. Strabismus was seen in $25 \%$ without ROP. Cats and $\operatorname{Tan}^{10}$ noted a similar incidence. This is higher than that noted in other studies which ranged from 9-13\%. ${ }^{11^{21}}$ As some children, in this prospective study, who did not develop any problems in the first 2 years of life have been lost to follow up, we may have overestimated the incidence of strabismus in this non ROP group. All the children with ROP developed early onset, non-accommodative strabismus. This has not been documented elsewhere. Kushner ${ }^{21}$ reported a high incidence of less common types of strabismus. Those with amblyopia responded well to occlusion therapy, unless there was another contributing factor. This again reflects the prospective nature of this study, with early detection and treatment.

Cats and $\operatorname{Tan}^{10}$ reported two cases of late onset retinal detachment. Tasman ${ }^{23}$ reported an increased incidence of retinal detachment and retinal and RPE degeneration in some teenagers with premature birth. It is important to state that our follow-up period is only 4 years or less in the majority of children. We have not seen any case of rhegmatogenous detachment after the neonatal period. Ten children have peripheral retinal scars related to cryotherapy and four have peripheral pigmentary changes.

Glaucoma is a well recognised complication of advanced $\mathrm{ROP}^{24}$ and may even occur in adults with stable cicatricial disease. ${ }^{25}$ The management of this difficult problem has been discussed by Andrew et al. ${ }^{26}$ Treatments include medical therapy, peripheral iridectomy, trabeculectomy, lensectomy, shunt implantation, and cilioablative procedures. We have one child with retinal detachment who required glaucoma surgery, in the form of trabeculectomy, to control pressures of $50 \mathrm{~mm} \mathrm{Hg}$. These are working well in the short term.

The increased survival of premature infants, with and without ROP, is posing a long term problem in terms of increased incidence of ocular problems such as strabismus, amblyopia, and refractive errors. We realise our sample is not a 
true representation of a full premature population, as many of the well infants have been lost to follow up. This explains our high incidence of severe disease. Despite this, we feel this study is important as it reflects a natural premature population in an active paediatric ophthalmology unit. Our study shows the major difference between children with and without ROP is in terms of the incidence of myopia and the age of onset of strabismus. We have reported a similar incidence of strabismus in both groups. The prognosis for poor vision and myopia is substantially higher with stage 3 disease. We recommend that all children with ROP require a lifelong follow up, even with a good retinal outcome. Parents, health care workers, and ophthalmologists need to be fully aware of these problems in the premature population, including the long term risk of retinal detachment, to ensure early referral and treatment.

1 Goggin M, O'Keefe M. Childhood blindness in the Rep. of Ireland - a national survey. Br $\mathcal{F}$ Ophthalmol 1991; 75: 425-9.

2 Valentine PH, Jackson JC, Kalina RE, Woodrum DE Increased survival of low birth weight infants: impact on the incidence of retinopathy of prematurity. Pediatrics $1989 ; 84$ : $442-5$.

3 Gibson DL, Sheps SB, Schechter MT, Wiggins S, McCormick AQ. Retinopathy of prematurity: a new epidemic? Pediatrics AQ. Retinopathy

4 Gibson DL, Sheps SB, Uh SH, Schecter MT, McCormick AQ. Retinopathy of prematurity-induced blindness: birth weight specific survival and the new epidemic. Pediatric 990; 86: 405-12.

5 Phelps DL. Retinopathy of prematurity: an estimate of vision loss in the United States - 1979. Pediatrics 1981; 67:924-6.

6 Cryotherapy for Retinopathy of Prematurity Cooperative Group. Multicenter trial of cryotherapy for retinopathy of prematurity: one-year outcome - structure and function. Arch Ophthalmol 1990; 108: 1408-16.

7 The Committee for the Classification of Retinopathy of
Prematurity. An international classification of retinopathy of prematurity. Arch Ophthalmol 1984; 102: 1130-4.

8 Cryotherapy for Retinopathy of Prematurity Cooperative Group. Multicenter trial of cryotherapy for retinopathy of prematurity: preliminary results. Arch Ophthalmol 1988; 106: 471-9.

9 Robinson R, O'Keefe $M$. Cryotherapy for retinopathy of prematurity - a prospective study. Br $\mathcal{F}$ Ophthalmol 1992 ; 76: 289-91.

10 Cats B, Tan K. Prematures with and without regressed retinopathy of prematurity: comparison of long-term (6-10 years) ophthalmological morbidity. 7 Pediatr Ophthalmol Strabismus 1989; 26: 271-5.

11 Kelly SP, Fielder AR. Microcornea associated with retinopathy of prematurity. Br f Ophthalmol 1987; 71: 201-3.

12 pathy of prematurity. Br Ophthalmol $1987 ; 71: 201-3$. nerve hypoplasia in infancy. $\mathcal{F} R$ Soc Med 1986; 79: 25-9.

13 Burgess $P$, Johnson A. Ocular defects in infants of extremely low birth weight and low gestational age. Br $\mathcal{F}$ Ophthalmo 1991; 75: 84-7.

14 Zeki SM, Dutton GN. Optic nerve hypoplasia in children. $\mathrm{Br}$ f Ophthalmol 1990; 74: 300-4.

5 Burke PB, O'Keefe M, Bowell R. Optic nerve hypoplasia encephalopathy and neurodevelopmental handicap. $\mathrm{Br} \mathcal{J}$ Ophthalmol 1991; 74: 236-9.

16 Gordan RA, Donziz PB. Myopia associated with retinopathy of prematurity. Ophthalmology 1986; 93: 1593-8.

17 Schaffer DB, Quinn GE, Johnson L. Sequelae of arrested mild retinopathy of prematurity. Arch Ophthalmol 1984; 102: retinopart

18 Gallo CG, Lennerstand G. Ocular morbidity in infants of very low birth weight. Br $\mathcal{F}$ Ophthalmol 1983; 67: 302-5.

19 Snir M, Nissenkorn I, Sherf I, Cohen S, Ben Sira I. Visual acuity, strabismus and amblyopia in premature babies with and without retinopathy of prematurity. Ann Ophthalmol 1988; 20: 256-8.

20 Nissenkorn I, Yassur Y, Mashkowski D, Sherf I, Ben-Sira I Myopia in premature babies with and without retinopathy of prematurity. BrF Ophthalmol 1983; 67: 170-3.

21 Kushner BJ. Strabismus and amblyopia associated with regressed retinopathy of prematurity. Arch Ophthalmol 1982; 100: 256-61.

22 Keith CG, Kitchen WH. Ocular morbidity in infants of very low birth weight. Brf Ophthalmol 1983; 67: 302-5.

23 Tasman W. Late complications of retrolental fibroplasia. Ophthalmology 1979; 86: $1724-40$.

24 McCormick AQ, Pratt-Johnson JA. Angle closure glaucoma in infancy. Can $\mathcal{F}$ Ophthalmol 1971; 6: 91-3.

25 Smith J, Shivitz I. Angle-closure glaucoma in adults with cicatricial retinopathy of prematurity. Arch Ophthalmol 1984; 102: 371-2.

26 Andrew JM, Pesin SR, Katz LJ, Tasman WS. Management of late-onset angle closure glaucoma associated with retinopathy of prematurity. Ophthalmology 1991; 98: 1093-8. 